Revue

Revue de l'histoire des religions

de Ihistoire des religions

$1 \mid 2016$

Varia

\title{
Patrick-Dominique LINCK, Histoire religieuse de la
}

Suède (1520-1930)

Éditions du Cerf, 2013

Frédérique Harry

\section{CpenEdition}

Journals

Édition électronique

URL : http://journals.openedition.org/rhr/8524

DOI : 10.4000/rhr.8524

ISSN : 2105-2573

Éditeur

Armand Colin

Édition imprimée

Date de publication : 1 mars 2016

Pagination : 134-136

ISBN : 978-2-200-93059-2

ISSN : 0035-1423

Référence électronique

Frédérique Harry, «Patrick-Dominique ıINCK, Histoire religieuse de la Suède (1520-1930) 》, Revue de I'histoire des religions [En ligne], 1 | 2016, mis en ligne le 05 avril 2016, consulté le 23 septembre 2020. URL : http://journals.openedition.org/rhr/8524 ; DOI : https://doi.org/10.4000/rhr.8524

Ce document a été généré automatiquement le 23 septembre 2020

Tous droits réservés 


\title{
Patrick-Dominique LINCK, Histoire religieuse de la Suède (1520-1930)
}

Éditions du Cerf, 2013

\author{
Frédérique Harry
}

\section{RÉFÉRENCE}

Patrick-Dominique LINCK, Histoire religieuse de la Suède (1520-1930), Éditions du Cerf, 2013, 485 p., 19,5 cm, $34 €$ (« Histoire »), ISBN 978-2-204-09612-6.

1 Patrick-Dominique Linck (PDL) fait face à un défi stimulant qui consiste à résumer quatre siècles d'histoire religieuse en 485 pages, bibliographie et index compris. Défi d'autant plus grand qu'il lui faut revenir sur la Réforme, la construction des orthodoxies, les piétismes, les réveils du xix siècle et la formation d'une Église du Peuple au début du $\mathrm{xx}^{\mathrm{e}}$ siècle.

2 Compte tenu de la rareté des travaux sur ce thème dans le champ universitaire français, l'ouvrage poursuit un objectif didactique en introduisant de façon détaillée l'histoire religieuse du royaume scandinave. Il est divisé en 31 chapitres qui facilitent une lecture historique et thématique. La majeure partie de cet ouvrage est consacrée aux $\mathrm{XIX}^{\mathrm{e}}$ et $\mathrm{Xx}^{\mathrm{e}}$ siècles, période où le champ religieux change radicalement le visage de la Scandinavie.

Les premiers chapitres traitent du passage à la Réforme, dont l'auteur souligne à juste titre le caractère progressif et irrégulier. PDL revient sur les étapes politiques qui marquent les débuts de la Réforme, du bain de sang de Stockholm en 1520 à l'arrivée de Gustav II Adolph sur le trône suédois. Il insiste à juste titre sur la logique de continuation qui prévaut à l'égard de l'héritage médiéval de l'Église suédoise. Il met en relief les enjeux qui séparent la centralisation de l'État et la réforme de l'Église, soucieuse d'une certaine autonomie et inquiète des tendances hétérodoxes des souverains Johan III et Karl IX. Les premiers chapitres illustrent la spécificité de la construction d'une Église d'État en Suède dans des termes ecclésiologiques bien 
différents de ceux constatés dans le royaume de Danemark-Norvège à la même époque. Concluant ce siècle en une quarantaine de pages, l'auteur propose un récapitulatif fort intéressant et particulièrement accessible sur les courants spirituels de la Réforme (ch. 3).

4 Sous l'ère de la liberté (1718-1771), le rôle de la religion évolue pour devenir « un facteur de cohésion [formant] la base de la morale» (p. 64). Mais l'unité religieuse et nationale voulue par le pouvoir et l'orthodoxie luthérienne est inquiétée par l'apparition des piétismes, radical, morave ou conservateur. Les premiers conventicules apparaissent dans les zones urbaines, comme par exemple à Stockholm, avec le groupe de la maison de Momma. Le clivage s'implante au sein même de l'Université d'Uppsala, augurant la rupture entre les pôles universitaires de la haute et de la basse Église au cours des siècles suivants. Le pouvoir, qui partage l'intérêt de l'orthodoxie pour la défense de l'unité religieuse du royaume, durcit les lois et interdit les conventicules en 1726. Dans le même temps, l'attitude à l'égard des cultes étrangers, notamment calvinistes, s'assouplit. Jusqu'au XIX ${ }^{e}$ siècle, la confession délimite donc les frontières du royaume et du peuple excluant les autres confessions de la communauté nationale.

Le XIX ${ }^{e}$ siècle nécessite près d'une vingtaine de chapitres et forme le principal objet de cet ouvrage. Ce déséquilibre apparent est justifié par l'ampleur des bouleversements socioreligieux qui apparaissent avec les réveils et redéfinissent progressivement les rapports entre l'État, l'Église et le peuple. Suite au mouvement de sécularisation qui commence, la conception territoriale et nationale de l'Église suédoise entre en conflit avec la lecture congrégationaliste prônée par les réveils. Cela s'enracine dans les débats de l'époque piétiste où la compréhension " territoriale ", qui considérait l'Église comme une association dans l'État, s'opposait à la « compréhension collégiale » qui souhaitait en faire une association libre. Au XIX siècle, ce conflit s'articule à une critique croissante du clergé par le laïcat qui prend parfois une forme anticléricale (ch. 19) sans empêcher des jeux d'influence réciproque entre l'Église suédoise luthérienne et les nouveaux mouvements. Les réveils, principalement luthériens jusque dans les années 1850 , sont l'objet de lourdes suspicions qui se cristallisent autour de la tenue des conventicules, la prédication et l'administration des sacrements par des laïcs. Mais ils renouvellent aussi la pensée et l'appareil ecclésiologique luthériens, divisant durablement - voire encore - la basse et la haute Église (ch.13). Le droit religieux se libéralise au terme de la première moitié $\mathrm{du}$ xIX ${ }^{e}$ siècle, autorisant sous une certaine forme la tenue de conventicules luthériens. Le décret royal de 1860 sur les confessions de foi étrangères marque un assouplissement envers les cultes considérés comme «étrangers ", à savoir les Églises dissidentes qui se sont entre-temps développées. Des Églises non-luthériennes, dont l'Église catholique, sont officiellement reconnues. En 1873, une nouvelle loi lève une partie des sanctions qui touchaient les cultes nonluthériens. Ces reconfigurations sont à l'aune de la transformation du rôle social, institutionnel et identitaire de l'Église en tant qu'actrice locale, territoriale et nationale. L'auteur analyse plus spécifiquement la sécularisation progressive - et partielle - de l'école, de l'aide sociale et des services d'État (ch. 15 et 22), ainsi que le développement parallèle de la diaconie (ch.17) et des œuvres protestantes (ch. 22 et 24). Ces développements ouvrent des pistes de réflexion stimulantes sur la construction du modèle social suédois au $\mathrm{xx}^{\mathrm{e}}$ siècle.

6 La fin du XIX ${ }^{e}$ siècle est marquée par la diversification des réveils et l'implosion de la mission intérieure luthérienne : l'Evangeliska Fosterlandsstiftelsen se divise et la Svenska 
Missionsförbundet est créée. Ce mouvement d'inspiration luthérienne repose sur un modèle congrégationaliste et se place entre les Églises libres et l'Église luthérienne. Il préfigure l'arrivée d'un mouvement interconfessionnel d'inspiration anglo-saxonne qui prône un «christianisme de l'alliance » (p. 350) et confirme la relativisation radicale de l'autorité religieuse institutionnelle et des identités confessionnelles héritées de l'orthodoxie. Les Églises apocalyptiques apparaissent à la fin du siècle (ch. 25) et annoncent l'essor du pentecôtisme après 1905.

Ces bouleversements vont de pair avec une privatisation croissante du vécu religieux qui profite d'un tissu communautaire plus indépendant pour remodeler les critères d'identification. Le rapport au dogme devient dans ce contexte une question épineuse qui fragilise les communautés - comment demeurer uni sans cadre dogmatique normatif? - au même titre qu'elle en permet l'expansion. Ce développement est important pour comprendre les formes variées de l'œcuménisme suédois au $\mathrm{xx}^{\mathrm{e}}$ siècle dont on connaît toute l'importance à l'échelle mondiale. Au début du $\mathrm{xx}^{\mathrm{e}}$ siècle donc, le paysage religieux suédois se décline de l'épiscopalisme au congrégationalisme radical, les théologies se sont pluralisées et le rapport à l'institution s'est relativisé. Mais les Églises libres, et notamment baptistes, se perçoivent toujours en marge de la norme luthérienne et de la société. Elles se regroupent donc, en 1905, pour organiser la défense de leurs intérêts et réclamer plus d'égalité.

Dans les chapitres 21 et suivants, l'auteur inscrit l'histoire plus contemporaine de l'Église suédoise et des Églises libres dans un contexte plus large qui prend en compte la libre-pensée et la montée du socialisme. La critique de l'Église constitue, en effet, un point central de l'idéologie sociale-démocrate qui considère la religion comme une affaire exclusivement privée : si la séparation de l'Église et de l'État apparaît dès 1897 dans le programme politique de la social-démocratie, le projet, quant à lui, n'aboutira, partiellement, qu'en l'an 2000. Au cours des années 1930, la social-démocratie adopte en effet la ligne "engbergienne » qui préfère une logique consensuelle pour laquelle l'Église devient une administration du fait religieux par l'État suédois. En somme, la logique d'Arthur Engberg, quoique influencée par le marxisme, témoigne d'une réadaptation sociale-démocrate de l'héritage luthéro-suédois, qui engage l'Église suédoise à devenir une Église du Peuple (p. 414). L'institution réactualise ainsi son rôle national et communautaire mais n'est pas à l'abri des tensions qui divisent l'aile nationaliste et l'aile sociale-démocrate au cours des années 1930.

9 Dans une perspective proche de la série Sveriges Kyrkohistoria, parue dans les années 2000 en Suède, cet ouvrage offre donc une lecture intéressante, car trop rare dans la recherche francophone, de l'histoire religieuse de la Suède jusque dans les années 1930. Sa richesse réside également dans l'exhaustivité historique et le souci de clarté, offrant, par exemple, des développements sur les influences théologiques, nécessaires à la compréhension des sociétés suédoise et scandinaves (ch. 3, 12 et 19). Une place plus importante accordée au comparatisme à l'échelle scandinave aurait toutefois permis de mettre en évidence la spécificité de l'histoire religieuse de la Suède par rapport aux autres pays nordiques. Quoi qu'il en soit, cet ouvrage éclaire magistralement l'histoire religieuse de la Suède depuis la Réforme et nourrira, sans nul doute, la réflexion sur la sécularisation et la laïcisation des sociétés européennes contemporaines. 


\section{AUTEURS}

\section{FRÉDÉRIQUE HARRY}

Université Paris-Sorbonne. 